\title{
Kajian Kinerja Sistem Polder sebagai Model Pengembangan Drainase Kota Semarang Bagian Bawah dengan Balanced Scorecard
}

\author{
Hari Nugroho \\ Departemen Teknik Sipil, Fakultas Teknik, Universitas Diponegoro \\ Jl. Prof. Soedarto, SH, Tembalang, Semarang 50275 \\ E-mail: harinugroho66@yahoo.co.id \\ Dwi Kurniani \\ Departemen Teknik Sipil, Fakultas Teknik, Universitas Diponegoro \\ Jl. Prof. Soedarto, SH, Tembalang, Semarang 50275 \\ E-mail:dwik_ani@yahoo.com
}

Mega Asiska

Program Studi Sarjana Teknik Sipil, Fakultas Teknik, Universitas Diponegoro

Jl. Prof. Soedarto, SH, Tembalang, Semarang 50275

E-mail: mega.asiska@gmail.com

Nuraini

Program Studi Sarjana Teknik Sipil, Fakultas Teknik, Universitas Diponegoro

J1. Prof. Soedarto, SH, Tembalang, Semarang 50275

E-mail: nuraini121993@gmail.com

\begin{abstract}
One of the technological flood control and rob in the big cities is the polder system that include drainage systems, retention ponds, levees that surround the area, as well as the pump and /floodgates, as the area of integrated water management system. Likewise, as the coastal city of Semarang in Indonesia has built some of the polder which has been in operation or under construction. To assess the success of the polder management, necessary for a study to determine the performance of the system in controlling the flood in Semarang. Assessment of performance of the system as a whole polder in this study used the concept of the Balanced Scorecard (BSC). The results of this study demonstrate the performance of the polder in Semarang is an ideal: Polder Tanah Mas (73.81 / 100), then Polder Banger (67.21 / 100), Polder Kali Semarang (58.70/100) and the Polder Tawang (58.65/100). The performance of the Polder system above can not be separated from the existence of an independent governing body and had been prepared much earlier. So the presence of the governing body needs to be prepared in the polder system development. To improve performance, the polder-existing polder in Semarang needs to be improved its performance by improving the performance indicators is still less based on this research primarily on indicators: financial, management agencies and learning and development.
\end{abstract}

Keywords: Polder Semarang, Performance, Balanced Scorecard.

\begin{abstract}
Abstrak
Salah satu teknologi pengendalian banjir dan rob di kota-kota besar adalah dengan sistem polder, yang meliputi sistem drainase, kolam retensi, tanggul yang mengelilingi kawasan, serta pompa dan/ pintu air, sebagai kawasan pengelolaan tata air yang terpadu. Demikian juga dengan Kota Semarang beberapa polder yang telah beroperasi dan beberapa masih dalam tahap pembangunan. Untuk menilai keberhasilan
\end{abstract}


pengelolaan polder, diperlukan adanya suatu kajian untuk mengetahui kinerja dari sistem tersebut dalam mengendalikan banjir dan rob di Kota Semarang. Penilaian kinerja dari sistem polder secara menyeluruh dalam penelitian ini digunakan konsep Balanced Scorecard (BSC). Hasil dari penelitian ini menunjukkan kinerja polder di Kota Semarang yang ideal adalah berturut-turut: Polder Tanah Mas dengan nilai (73,81/100), Polder Banger (67,21/100), Polder Kali Semarang (58,70/100) dan Polder Tawang (58,65/100). Kinerja dari Sistem Polder diatas tidak dapat dilepaskan dari keberadaan badan pengelola yang mandiri dan yang telah dipersiapkan jauh sebelumnya. Sehingga keberadaan badan pengelola perlu dipersiapkan dalam pengembangan sistem polder. Untuk meningkatkan kinerjanya maka polder-polder yang sudah ada di Kota Semarang perlu ditingkatkan kinerjanya dengan meningkatkan kinerja: keuangan, badan pengelola, dan pembelajaran dan pengembangan.

Kata-kata kunci: Polder Kota Semarang, Kinerja, Balanced scorecard.

\section{Pendahuluan}

Kota Semarang sebagai Ibukota Provinsi Jawa Tengah mengalami pertumbuhan yang pesat dalam berbagai aspek, baik aspek sosial, ekonomi maupun perdagangan. Selain dampak positif akan pertumbuhan yang tersebut, Kota Semarang juga mengalami persoalan lingkungan yang serius. Di wilayah Semarang bagian utara yang dekat dengan bagian pantai (lebih dikenal dengan Semarang Bawah), muncul berbagai permasalahan lingkungan seperti banjir dan rob. Banjir dan rob telah lama menjadi persoalan yang tidak mudah diatasi, utamanya di Kecamatan Semarang Utara. Kawasan yang wilayahnya menjadi langganan rob dan banjir adalah Kelurahan Tambakmulyo, Tambakrejo, Tanjung Mas serta Bandarharjo. Banjir di kawasan tersebut rata-rata mencapai ketinggian antara 30 dan $40 \mathrm{~cm}$, tetapi lokasi yang paling parah adalah Tambakmulyo dan Tambakrejo, karena memang paling dekat dengan pantai (Bappeda Kota Semarang, 2013).

Untuk mengatasi banjir dan rob di tempat diatas, Pemerintah telah membangun sistem polder. Sistem ini merupakan salah satu teknologi pengendalian banjir dan rob yang diterapkan untuk mengatasi permasalahan banjir dan rob di kotakota besar, yaitu suatu cara penanggulangan banjir dengan bangunan fisik yang meliputi sistem drainase, kolam retensi, tanggul yang mengelilingi kawasan, serta pompa dan/ pintu air, sebagai kawasan pengelolaan tata air yang terpadu.

Beberapa polder yang telah beroperasi seperti Polder Kali Semarang, Polder Tawang, Polder Tanah Mas maupun yang masih dalam tahap pembangunan seperti Polder Banger perlu dilakukan kajian untuk menilai kinerja dari sistem ini dalam mengendalikan banjir. Penilaian kinerja dilakukan secara menyeluruh terhadap unsur teknis maupun non teknis sistem polder karena besarnya peran unsur-unsur non teknis terhadap kinerja sistem polder.

\section{Permasalahan}

Hasil kajian pada instansi terkait seperti Bappeda, PSDA, ESDM, dinas Pariwisata dan DPRD, observasi lapangan, wawancara mendalam (indepth interview), dan diskusi kelompok terfokus (Focus Group Discussion), secara umum dapat disarikan keberadaan kolam retensi Tawang Kota Lama dan mungkin juga berlaku untuk Polderpolder yang lain dihadapkan berbagai permasalahan yang terancam kelestariannya. Ada dua faktor penyebab permasalahan tersebut, yakni faktor struktural dan nonstruktural.

Secara struktural, terkait dengan masalah implementasi kebijakan pengelolaan kolam retensi dan dampak lingkungan yang terjadi. Intinya, kolam retensi Tawang Kota Lama belum berfungsi secara optimal untuk pengendali banjir dan rob, belum dapat melindungi kawasan cagar budaya Kota Lama dan belum dapat berfungsi sebagai objek wisata kota.

Secara nonstruktural, yakni terkait dengan tanggungjawab masyarakat di sekitar Kolam Retensi (polder) sebagai pengguna manfaat Kolam Retensi (polder) yang belum meniliki kontribusi secara nyata untuk membangun polder berkelanjutan. Hal ini dibuktikan oleh peran pemangku kepentingan dan kepedulian masyarakat terhadap Kolam Retensi (polder).

Beberapa pakar mengatakan sangat risau melihat kondisi sebagai contoh kolam retensi Tawang yang semakin tidak terawat. Karena di area kolam retensi dinilai tidak indah lagi seperti masa lalu, tidak aman, tidak nyaman dan tidak produktif. Banyak sampah bertebaran, taman tidak asri, jarang dikuras sehingga kualitas air tidak baik bahkan sering bau busuk. Jika siang dijadikan tempat berdagang sektor informal, sehingga merusak keindahan.

Pada malam hari sering digunakan sebagai area praktek prostitusi dan minum-minuman keras bahkan juga kadang menjadi ajang perkelahian. 
Terhitung sudah 6 kali terjadi insiden yang menelan korban jiwa, tiga anak-anak terpeleset masuk kolam dan tiga orang dewasa karena mabuk terpelanting ke kolam. Menurut Lurah Tanjung Mas Mardiyono, tahun 2007 dijanjikan oleh pemerintah kota, bahwa kolam retensi Tawang akan diserahkan hak pengelolaan kepada masyarakat kelurahan Tanjung Mas, tetapi hingga sekarang tidak terealisasi. Namun demikian dapat disarikan bahwa kendatipun permasalahan eksternal begitu kompleks, tetapi keberadaan kolam retensi masih sangat dibutuhkan oleh masyarakat untuk pengendalian banjir dan rob. Bagaimanapun kolam retensi tersebut mempunyai peran yang besar dalam melindungi permukiman penduduk, khususnya warga Tanjung Mas dan Purwodinatan terhadap ancaman banjir dan rob, jika terjadi hujan ekstrim bersamaan dengan terjadinya rob.

Berangkat dari berbagai permasalahan yang mengakibatkan disfungsi kolam retensi (polder) sebagaimana diuraikan di atas, maka sangat perlu dilakukan kajian untuk mencari alternatif solusi agar kolam retensi Tawang dapat berfungsi optimal. Atas dasar konstruksi pikir rasional, paradigma kebijakan sangat diperlukan pemikiran dan kajian kritis model pengelolaan polder berkelanjutan yang berbasis masyarakat.

Sebagai langkah awal perlu dilakukan kajian dasar untuk menilai kinerja polder yang ada di Semarang. Selanjutnya hasil kajian ini diharapkan dapat memberikan masukan kepada pengelola berbagai hal dalam upaya peningkatan kinerjanya. Hal demikian berlaku juga bagi polder-polder lainnya yaitu Polder Kali Semarang, Polder Tanah Mas dan Polder Banger yang masih dalam tahap penyelesaian pembangunan.

\section{Penilaian kinerja}

Pengelolaan suatu lembaga atau institusi yang berkaitan dengan kebutuhan dan kepentingan publik dituntut untuk melaksanakan kegiatan secara professional dan memiliki kinerja yang dapat memuaskan stakeholders. Pengukuran kinerja atau yang dikenal dengan performance benchmarking diperlukan agar diketahui serta dapat ditentukan peningkatan kinerjanya.

Banyak metode yang digunakan untuk mengukur kinerja suatu organisasi antara lain: Malcom Baldridge National Quality Award (MBNQA), Balanced Scorecard (BSC), Six Sigma dan lainlain. Diantara metode-metode tersebut, BSC merupakan salah satu metode yang sangat popular digunakan dalam dekade terakhir.
Balance Scorecard menggunakan empat perspektif BSC yang menyatakan sebagai Bidang Kinerja Kritis (Critical Performance Area), yaitu: pengguna, keuangan, proses internal dan pembelajaran (Kementrian PU, 2013).

Penjelasannya sebagai berikut :

1. Pengguna: bagaimana kepuasan thd pengguna/ penerima manfaat polder

2. Keuangan: bagaimana keuangan/dana agar polder bisa berlangsung keberlanjutannya

3. Proses Internal: bagaimana fungsi polder memenuhi harapan masyarakat

4. Pembelajaran: bagaimana inovasi pelayanan polder ke depan

\section{Metode Balance Scorecard}

Balance Scorecard adalah alat manajemen berupa laporan terstruktur yang digunakan untuk melacak pelaksanaan suatu kegiatan. Dibandingkan dengan metode lain, metode ini paling banyak dikenal dan digunakan. Konsep BSC pertama kali disampaikan oleh Kaplan dan Norton 1992. Kaplan (1992) mengemukakan bahwa Balance Scorecard dapat menjawab empat pertanyaan pokok yaitu 1). Bagaimana kepuasan pengguna; 2) bagaimana pengaturan dana 3) apa yang harus dan akan kita laksanakan dan 4) apa yang akan dikembangkan. Sebagaimana dalam Gambar 1 dibawah ini.

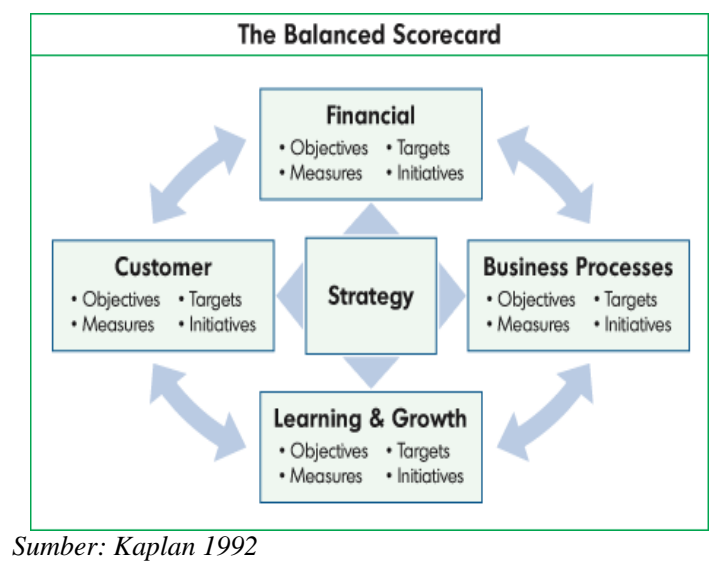

Gambar 1. Diagram balance scorecard

Penggunaan balance scorecard dalam pengelolaan sumber daya air telah banyak dilakukan antara lain IWMI (International Water Management Institute) mengembangkan teori ini untuk mengukur kinerja pengelolaan air. Berdasarkan kajian diatas metode Balance Scorecard dicoba diterapkan untuk mengukur kinerja pengelolaan polder.

\section{Penilaian kinerja polder dengan balanced scorecard}

Penilaian kinerja menggunakan 5 (lima) Bidang Kinerja Kritis (BKK). Masing-masing BKK terdiri 
dari beberapa indikator penilaian, untuk pencapaian sempurna di total nilai indikator dalam satu BKK adalah 100.

Bidang kinerja kritis terdiri dari:

1. Bidang kinerja kritis badan pengelola (Tabel 1)

2. Bidang kinerja kritis pengguna (Tabel 2)

3. Bidang kinerja kritis dana (Tabel 3)

4. Bidang kinerja kritis proses internal (Tabel 4)

5. Bidang kinerja kritis pembelajaran dan pengembangan (Tabel 5)

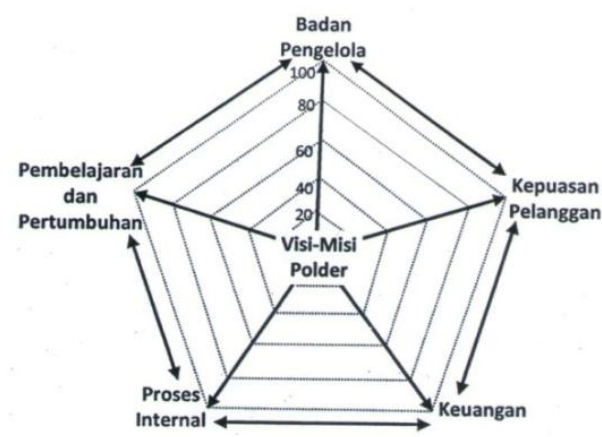

Gambar 2. Diagram penilaian kinerja polder dengan balance scorecard
Teknik analisa data dilakukan dengan metode kuantitatif dengan mengolah data kuisoner dengan memberikan skala penilaian 0-100 untuk setiap indikator yang dinilai. Untuk membandingkan hasil ketiga polder yang akan dinilai dianggap masing-masing kinerja mempunyai bobot yang sama sehingga Nilai tertinggi mempunyai kinerja yang paling baik. Setelah semua indikator dinilai, lalu dilakukan perhitungan bobot dari masingmasing bidang kinerja kritis. Pembobotan dilakukan dengan menggunakan metode AHP (Analitic Hierarchy Process), yaitu dengan menggunakan kuisioner yang diberikan kepada narasumber. Hasil pembobotan kemudian dijumlahkan untuk menentukan skor hasil kinerja masing-masing polder.

\section{Wilayah Kajian}

Kajian Kinerja Polder dengan Metode Balance Scorecard dilakukan pada empat polder yang ada di Kota Semarang, yaitu Polder Kali Semarang, Polder Banger, Polder Tanah Mas dan Polder Tawang sebagaimana disajikan dalam Gambar 3 di bawah.

Tabel 1. Range metode balance scorecard bidang kinerja kritis badan pengelola

\begin{tabular}{|c|c|c|}
\hline Indikator yang dinilai & Kondisi saat penilaian & Nilai \\
\hline \multirow[t]{4}{*}{ Status pengelola polder } & - Tidak ada pengelola & 0 \\
\hline & $\begin{array}{l}\text { - Sudah ada pengelola dan TUPOKSI belum baik dan belum } \\
\text { berbadan hukum. }\end{array}$ & 5 \\
\hline & $\begin{array}{l}\text { - Sudah ada pengelola dan TUPOKSI sudah baik tapi belum } \\
\text { berbadan hukum }\end{array}$ & 7 \\
\hline & $\begin{array}{l}\text { - Sudah ada pengelola dan TUPOKSI yang baik dan sudah } \\
\text { berbadan hukum. }\end{array}$ & 10 \\
\hline Pemahaman Visi dan & - Pemahaman kurang & 5 \\
\hline \multirow[t]{2}{*}{ Misi } & - Pemahaman tugas baik tapi pemahaman visi dan misi kurang & 10 \\
\hline & - Pemahaman tugas dan visi misi sudah baik & 15 \\
\hline \multirow{3}{*}{$\begin{array}{l}\text { Kemandirian badan } \\
\text { pengelola }\end{array}$} & - Terdiri dari unsur pemerintah, cendekiawan dan masyarakat & 5 \\
\hline & - Terdiri dari cendekiawan dan masyarakat & 10 \\
\hline & - Terdiri dari masyarakat saja & 15 \\
\hline \multirow[t]{2}{*}{ Pengelolaan polder } & $\begin{array}{l}\text { - Jarang melakukan rapat koordinasi dan OP dilakukan sendiri } \\
\text { oleh pelaksana }\end{array}$ & 10 \\
\hline & $\begin{array}{l}\text { - Sering dilakukan rapat koordinasi dan OP dilakukan oleh yang } \\
\text { berkepentingan }\end{array}$ & 20 \\
\hline \multirow[t]{3}{*}{ Keterwakilan masyarakat } & $\begin{array}{l}\text { - Pengelola melibatkan masyarakat namun belum semua } \\
\text { kepentingan terwakili dan keputusan tidak berdampak langsung }\end{array}$ & 5 \\
\hline & $\begin{array}{l}\text { - Pengelola sudah menampung pendapat masyarakat namun belum } \\
\text { mencerminkan demokrasi sepenuhnya }\end{array}$ & 10 \\
\hline & $\begin{array}{l}\text { - Pengelola sudah melibatkan masyarakat dan sudah } \\
\text { mencerminkan demokrasi sepenuhnya }\end{array}$ & 20 \\
\hline \multirow[t]{2}{*}{$\begin{array}{l}\text { Implementasi hasil rapat } \\
\text { dengan masyarakat }\end{array}$} & $\begin{array}{l}\text { - Keputusan yang dibuat dalam rapat dengan masyarakat tidak } \\
\text { berdampak langsung }\end{array}$ & 10 \\
\hline & $\begin{array}{l}\text { - Keputusan yang dibuat dalam rapat dengan masyarakat } \\
\text { berdampak langsung }\end{array}$ & 20 \\
\hline
\end{tabular}


Tabel 2. Range metode balance scorecard bidang kinerja kritis kepuasan pelanggan

\begin{tabular}{lccc}
\hline \multicolumn{1}{c}{ Indikator yang dinilai } & & \multicolumn{1}{c}{ Kondisi saat penilaian } & Nilai \\
\hline Pemanfaatan lahan & - & Lahan didominasi oleh lingkungan bisnis & 5 \\
& - & Lahan didominasi oleh pemukiman biasa & 10 \\
\hline Tingkat kesadaran & - & Tingkat kesadaran kurang & 3 \\
masyarakat oleh & - & Tingkat kesadaran cukup & 5 \\
keberadaan polder & - & Tingkat kesadaran baik & 10 \\
\hline Pengaruh genangan & - & Pengaruh banjir dan rob bagi kehidupan kurang & 5 \\
& - & Pengaruh banjir dan rob bagi kehidupan sedang & 10 \\
& - & Pengaruh banjir dan rob bagi kehidupan besar & 15 \\
\hline Jaminan kemampuan & - & Tidak ada jaminan mampu melindungi masyarakat & 5 \\
polder & - & Mampu melindungi masyarakat sedang & 10 \\
& - & Mampu melindungi masyarakat baik & 15 \\
\hline Kualitas air & - & Tidak dipantau & 5 \\
& - & Ada pemantauan tapi tidak ada upaya perbaikan & 10 \\
\hline Feed back pelanggan & - & Dipantau dan ada upaya perbaikan & 15 \\
& - & Belum pernah dilakukan survey kepuasan pelanggan & 0 \\
& - & Pernah dilakukan survey tapi jarang & 10 \\
\hline Keluhan dan penanganan & - & Secara periodik dilakukan survey & 15 \\
pelanggan & - & Tidak ada sarana pengaduan masyarakat & 0 \\
& & Keluhan pelanggan diterima dengan baik tapi tidak segera & 5
\end{tabular}

Tabel 3. Range metode balance scorecard bidang kinerja kritis keuangan

\begin{tabular}{|c|c|c|}
\hline Indikator yang dinilai & $\begin{array}{l}\text { Kondisi saat penilaian } \\
\end{array}$ & Nilai \\
\hline Sumber dana & - Dari pemerintah/bantuan LN & 5 \\
\hline \multirow[t]{3}{*}{ pembangunan } & - Dari pemerintah dan masyarakat & 10 \\
\hline & - Murni dari masyarakat & 15 \\
\hline & - Dari masyarakat dan investor & 20 \\
\hline \multirow[t]{4}{*}{ Dana OP } & - Dari pemerintah/bantuan LN & 5 \\
\hline & - Dari pemerintah dan masyarakat & 10 \\
\hline & - Murni dari masyarakat & 15 \\
\hline & - Dari masyarakat dan investor & 20 \\
\hline \multirow{3}{*}{$\begin{array}{l}\text { Penentuan tarif } \\
\text { penarikan dana dari } \\
\text { masyarakat }\end{array}$} & - Sama & 5 \\
\hline & - Berdasar luasan tanah & 15 \\
\hline & - Berdasarkan kemauan dan kemampuan membayar & 20 \\
\hline \multirow[t]{3}{*}{ Kecukupan dana } & - Dana kurang & 5 \\
\hline & - Dana cukup & 15 \\
\hline & - Dana melebihi & 25 \\
\hline \multirow[t]{3}{*}{$\begin{array}{l}\text { Perencanaan dan } \\
\text { transparansi keuangan }\end{array}$} & $\begin{array}{l}\text { - Belum dilakukan perencanaan pemasukan keuangan dan belum } \\
\text { ada laporan keuangan }\end{array}$ & 5 \\
\hline & $\begin{array}{l}\text { - Sudah dilakukan perencanaan pemasukan keuangan dan belum } \\
\text { ada laporan keuangan }\end{array}$ & 10 \\
\hline & $\begin{array}{l}\text { - Sudah dilakukan perencanaan pemasukan keuangan dan ada ada } \\
\text { laporan keuangan }\end{array}$ & 15 \\
\hline
\end{tabular}

\section{Hasil Penilaian}

Setelah dilakukan identifikasi dengan bobot yang sama dengan menggunakan metode AHP, lalu dilakukan identifikasi dengan pembobotan yang berbeda. Hal ini ditujukan agar dapat diketahui keseimbangan sistem polder dilihat dari sisi finansial dan nonfinasial. Dalam hal ini bidang kinerja non finansial maliputi kepuasan pelanggan, badan pengelola, proses internal dan pembelajaran dan pengembangan. Dengan pembobotan tersebut, maka scoring penilaian kinerja polder dengan menggunakan Balance Scorecard pada Tabel 6 dan Gambar 3 
Tabel 4. Range metode balance scorecard bidang kinerja kritis proses internal

\begin{tabular}{|c|c|c|}
\hline Indikator yang dinilai & Kondisi saat penilaian & Nilai \\
\hline $\begin{array}{l}\text { Pemahaman staf } \\
\text { terhadap pengelolaan } \\
\text { dan visi dan misi }\end{array}$ & $\begin{array}{l}\text { - Pemahaman kurang } \\
\text { - Pemahaman cukup baik }\end{array}$ & $\begin{array}{c}5 \\
10\end{array}$ \\
\hline $\begin{array}{l}\text { Strategi pengendalian } \\
\text { muka air }\end{array}$ & $\begin{array}{l}\text { - Belum ada SOP } \\
\text { - Sudah ada SOP tanpa pompa cadangan } \\
\text { - Sudah ada SOP dengan pompa cadangan }\end{array}$ & $\begin{array}{c}5 \\
10 \\
15\end{array}$ \\
\hline $\begin{array}{l}\text { Perencanaan OP } \\
\text { polder }\end{array}$ & $\begin{array}{l}\text { - Tidak ada perencanaan OP polder } \\
\text { - Memiliki rencana OP yang difokuskan pada perencanan untuk } \\
\text { memperoleh anggaran yang akan dilakuan } \\
\text { - Memiliki rencana OP jangka panjang dan pendek }\end{array}$ & $\begin{array}{c}5 \\
10 \\
15\end{array}$ \\
\hline Petugas OP polder & $\begin{array}{l}\text { - Petugas kurang mampu melaksanakan OP dengan baik } \\
\text { - Petugas mampu melaksanakan OP dengan baik }\end{array}$ & $\begin{array}{c}5 \\
15\end{array}$ \\
\hline Sistem Administrasi & $\begin{array}{l}\text { - Baik } \\
\text { - Bai tapi pengarsipan belum baik dan tertib } \\
\text { - Baik dan sudah ada pengarsipan dengan baik }\end{array}$ & $\begin{array}{c}5 \\
10 \\
15\end{array}$ \\
\hline $\begin{array}{l}\text { Bangunan sarana dan } \\
\text { prasarana }\end{array}$ & $\begin{array}{l}\text { - Bangunan belum sesuai dengan kaidah teknik } \\
\text { - Bangunan sudah sesuai dengan kaidah teknik tanpa memperhatikan } \\
\text { kenyamanan } \\
\text { - Bangunan sudah sesuai dengan kaidah teknik dan memperhatikan } \\
\text { kenyamanan } \\
\text { - Bangunan sudah sesuai dengan kaidah teknik dan memperhatikan } \\
\text { kenyamanan serta sebagai tambahan income dari pengelolaan }\end{array}$ & $\begin{array}{l}0 \\
5 \\
10 \\
15\end{array}$ \\
\hline $\begin{array}{l}\text { Pengumpulan dan } \\
\text { pemanfaatan data }\end{array}$ & $\begin{array}{l}\text { - Tidak ada data yang dikumpulkan } \\
\text { - Data dikumpulkan secara sporadis } \\
\text { - Data dikumpulkan secara rutin } \\
\text { - Data dikumpulkan dan disimpan dengan baik }\end{array}$ & $\begin{array}{c}0 \\
5 \\
8 \\
10\end{array}$ \\
\hline
\end{tabular}

Tabel 5. Range Metode Balance Scorecard bidang kinerja kritis pembelajaran dan Pengembangan

\begin{tabular}{|c|c|c|}
\hline Indikator yang dinilai & Kondisi saat penilaian & Nilai \\
\hline Perencanaan pelatihan & $\begin{array}{l}\text { - Tidak ada rencana pelatihan pada staff pelaksana } \\
\text { - Ada rencana pelatihan pada staf pelaksana sesuai kebutuhan } \\
\text { - Ada rencana pelatihan pada staf pelaksana secara jangka pendek dan } \\
\text { jangka panjang }\end{array}$ & $\begin{array}{c}0 \\
10\end{array}$ \\
\hline Penilaian kinerja staff & $\begin{array}{l}\text { - Tidak ada sistem penilaian } \\
\text { - Ada sistem penilaian tapi tidak terkait dengan jenjang karier } \\
\text { - Ada sistem penilaian dan terkait dengan jenjang karier } \\
\text { - Ada sistem penilaian dan terkait dengan penjenjangan karier }\end{array}$ & $\begin{array}{l}0 \\
5 \\
10 \\
15\end{array}$ \\
\hline $\begin{array}{l}\text { Penilaian suasana } \\
\text { kerja }\end{array}$ & $\begin{array}{l}\text { - Belum ada sarana penyampaian keluhan } \\
\text { - Ada sarana penyampaian keluhan namun tidak ditanggapi dengan } \\
\text { sungguh-sungguh } \\
\text { - Ada sarana penyampaian keluhan dan segera ditindak lanjuti }\end{array}$ & $\begin{array}{c}0 \\
10\end{array}$ \\
\hline $\begin{array}{l}\text { Pengembangan sistem } \\
\text { informasi }\end{array}$ & $\begin{array}{l}\text { - Tidak adap pengembangan sistem informasi } \\
\text { - Pengembangan sistem informasi belum terintegrasi dengan pengelolaan } \\
\text { polder } \\
\text { - Ada rencana jangka pendek dan panjang yang sesuai dengan sasaran } \\
\text { rencana pengembangan pengelolaan }\end{array}$ & $\begin{array}{c}0 \\
10\end{array}$ \\
\hline $\begin{array}{l}\text { Pengembangan } \\
\text { peralatan }\end{array}$ & $\begin{array}{l}\text { - Tidak ada rencana pengembangan peralatan } \\
\text { - Ada pengembangan peralatan namun masih bersifat insidentiil } \\
\text { - Ada rencana pengembangan peralatan secara jangka pendek dan panjang }\end{array}$ & $\begin{array}{c}0 \\
10 \\
20\end{array}$ \\
\hline $\begin{array}{l}\text { Pengembangan sistem } \\
\text { pengeloalaan }\end{array}$ & $\begin{array}{l}\text { - Tidak ada rencana pengembangan sistem pengelolaan } \\
\text { - Ada pengembangan sistem pengelolaan namun masih bersifat insidentiil } \\
\text { - Ada rencana pengembangan sistem pengelolaan secara jangka pendek } \\
\text { dan panjang }\end{array}$ & $\begin{array}{c}0 \\
10 \\
20\end{array}$ \\
\hline
\end{tabular}




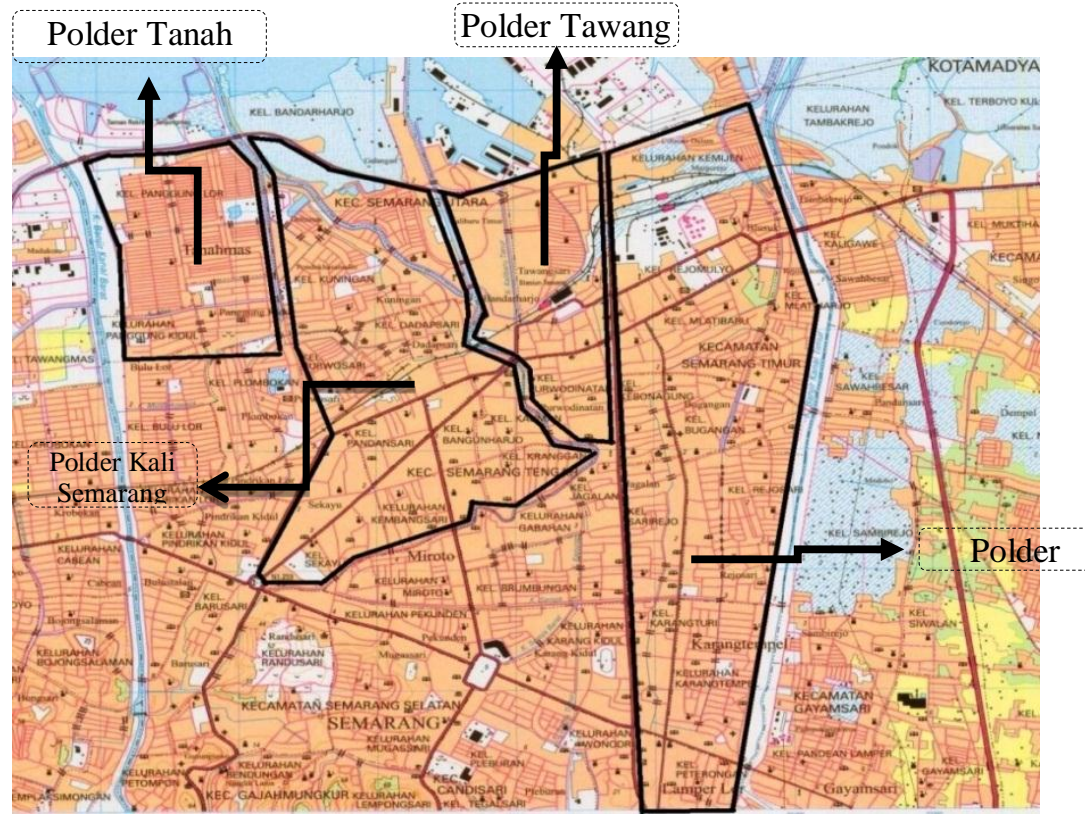

Gambar 3. Peta lokasi polder di Semarang

Tabel 6. Hasil penilaian kinerja dengan balanced scorecard

\begin{tabular}{|c|c|c|c|c|c|c|c|c|}
\hline \multirow{2}{*}{$\begin{array}{c}\text { Polder } \\
\text { Bidang kritis }\end{array}$} & \multicolumn{2}{|c|}{ Kali Semarang } & \multicolumn{2}{|c|}{ Banger } & \multicolumn{2}{|c|}{ Tanah Mas } & \multicolumn{2}{|c|}{ Tawang } \\
\hline & Nilai & $\begin{array}{l}\text { Nilai } \\
\text { bobot }\end{array}$ & Nilai & $\begin{array}{c}\text { Nilai } \\
\text { bobot }\end{array}$ & Nilai & $\begin{array}{l}\text { Nilai } \\
\text { bobot }\end{array}$ & Nilai & $\begin{array}{l}\text { Nilai } \\
\text { bobot }\end{array}$ \\
\hline Keuangan (19\%) & 40 & 7,60 & 65 & 12,35 & 90 & 17,10 & 35 & 6,65 \\
\hline Kepuasan pelanggan $(20 \%)$ & 58 & 11,66 & 38 & 7,60 & 63 & 12,60 & 70 & 14,00 \\
\hline Badan pengelola (27\%) & 50 & 13,50 & 90 & 24,30 & 87 & 23,49 & 62 & 16,74 \\
\hline Proses internal (18\%) & 88 & 15,84 & 90 & 16,20 & 75 & 13,50 & 75 & 13,50 \\
\hline $\begin{array}{l}\text { Pembelajaran dan } \\
\text { pengembangan }(16 \%)\end{array}$ & 60 & 9,60 & 65 & 10,40 & 55 & 8,80 & 45 & 7,20 \\
\hline Jumlah & & 58,70 & & 67,21 & & 73,81 & & 58,65 \\
\hline
\end{tabular}
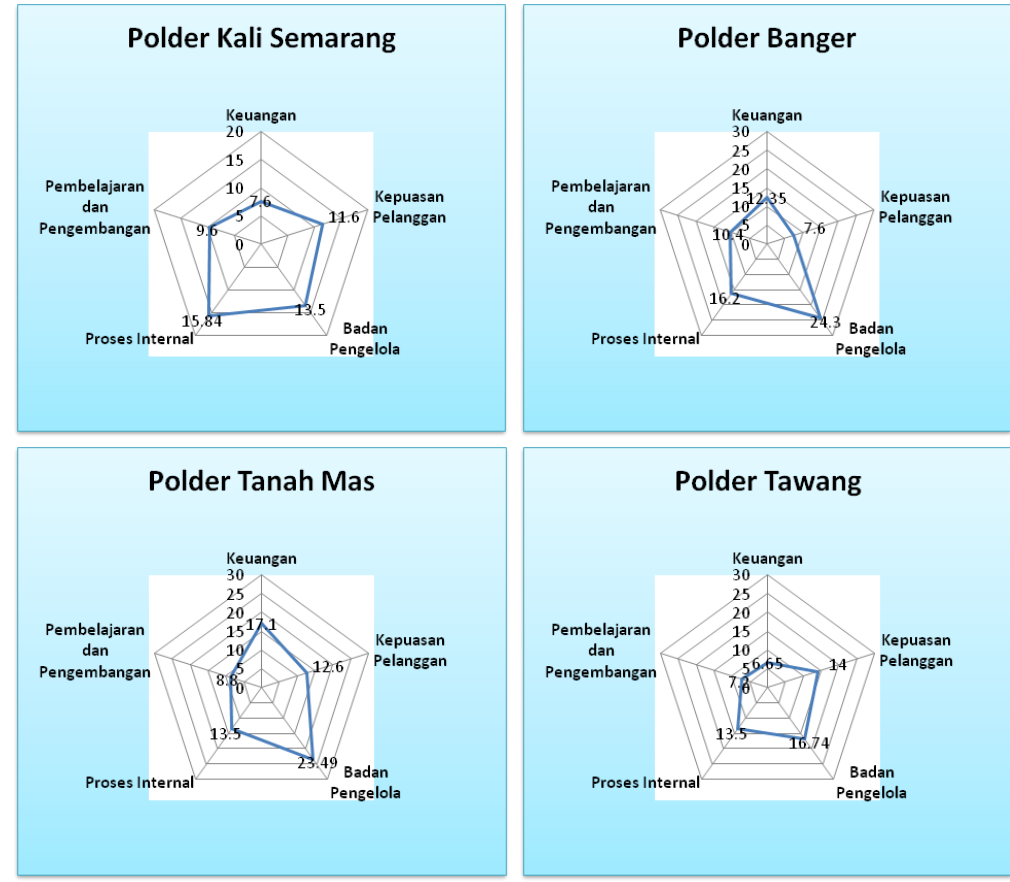

Gambar 4. Diagram hasil penilaian kinerja polder Kali Semarang, Banger, Tanah Mas dan polder Tawang 


\section{Analisa dan Pembahasan}

Polder Kali Semarang ini memiliki nilai keuangan 40/100. Angka tersebut dikatakan cukup rendah, dan dinilai belum bisa dikatakan mandiri dalam hal pengelolaannya. Keberadaan Badan Pengelola Pada Polder Kali Semarang ini memiliki nilai $50 / 100$, dikarenakan badan pengelolaannya yang masih kurang terstruktur dan keterlibatan masyarakat yang kurang terwakilkan.

Pada Polder Banger kelemahan yang utama adalah kepuasan pelanggan dengan nilai 38/100. Hal ini jelas terjadi, karena belum sempurnanya Polder ini beroperasi. Namun untuk kriteria lain cukup baik karena dipersiapkan cukup awal.

Polder Tanah Mas memiliki nilai tertinggi dari pembobotan polder-polder lainnya, karena dikelola oleh masyarakat. Proses yang adil dan transparan ini menjadikan P5L suatu paguyuban yang cukup mandiri dari finansialnya. Keunggulan pada badan pengelola dimana anggotanya sendiri berasal dari masyarakat setempat yang memiliki nasib yang sama membuat tergugah untuk berusaha sendiri memberantas genangan air yang setiap tahun menganggu. Namun untuk aspek pembelajaran dan pengembangan perlu lebih ditingkatkan karena nilainya 55/100.

Polder Tawang ada 2 indikator yang perlu dipacu. Yaitu keuangan nilai 35/100 dan pembelajaran dan pengembangan perlu lebih ditingkatkan karena nilainya 45/100. Perlu adanya rencana partisipasi masyarakat dalam hal keuangan dan pengembangan sistem pengelolaannya di masa mendatang.

Secara Umum Pengelolaan Polder Tanah Mas paling ideal dengan nilai $(73,81 / 100)$ kemudian Polder Banger $(67,21 / 100)$, Polder Kali Semarang $(58,70 / 100)$ dan Polder Tawang $(58,65 / 100)$.

\section{Kesimpulan}

Dari hasil penelitian ini dapat diambil kesimpulan sebagai berikut:

1. Kinerja Sistem Polder Sebagai Model Pengembangan Drainase Kota Semarang Bagian Bawah Dengan Balanced Scorecard menghasilkan penilaian kinerja: Polder Tanah Mas dengan nilai (73,81/100), kemudian
Polder Banger (67,21/100), Polder Kali Semarang $(58,70 / 100)$ dan Polder Tawang $(58,65 / 100)$.

2. Polder-polder tersebut memiliki efektifitas yang tinggi dalam penanggulangan banjir dan genangan di kota Semarang.

3. Kinerja dari Sistem Polder tidak dapat dilepaskan dari keberadaan badan pengelola yang baik, mandiri dan yang telah dipersiapkan jauh sebelumnya dalam mengelola sistem polder.

4. Model pengelolaan yang berbasis masyarakat dan dukungan dari instansi pemerintah merupakan model yang paling sesuai dalam pengelolaan polder di Kota Semarang.

\section{Saran}

Dari hasil penelitian ini diberikan saran sebagai berikut:

1. Kinerja dari sistem polder tidak dapat dilepaskan dari keberadaan badan pengelola yang baik sehingga keberadaan badan pengelola perlu dipersiapkan dalam pengembangan sistem polder.

2. Perlunya partisipasi aktif dari masyarakat dalam pengelolaan sistem polder.

3. Polder-polder yang sudah ada di Kota Semarang perlu ditingkatkan kinerjanya dengan meningkatkan kinerja indikator yang masih kurang berdasarkan penelitian ini.

\section{Daftar Pustaka}

Bappeda Kota Semarang, 2013. Studi Pengendalian Banjir dan Rob Kota Semarang

Kementerian PU, 2013. Penilaian Kinerja Polder dengan Balanced Scorecard, Draft, Jakarta.

Robert S., Kaplan and David P., Norton, 1992. The Balanced Scorecard - Measures that Drive Performance, Harvard Business Review.

Witteveen +Bos, 2009. Detailed Design Report, Development Pilot Polder Semarang and Guideline Polder Development. 